\title{
Aplikasi GIS Klasifikasi Tingkat Kerawanan Banjir Wilayah Kabupaten Bandung Menggunakan Metode Weighted Product
}

\author{
Eko Darwiyanto ${ }^{\# 1}$, Bintang Putra Binawan ${ }^{\# 2}$, Danang Junaedi ${ }^{\# 3}$ \\ \# Fakultas Informatika, Universitas Telekom \\ Jl Telekomunikasi 1, Dayeuhkolot, Bandung, Jawa Barat, Indonesia \\ 1ekodarwiyanto@telkomuniversity.ac.ic \\ ${ }^{2}$ bintangabun@gmail.com \\ ${ }^{3}$ danangjunaedi@telkomuniversity.ac.id
}

\begin{abstract}
Flooding was problem yearly in Kabupaten Bandung. When flooding occured several days, usually aids came for its victims. Badan Penanggulangan Bencana Daerah (BPBD) has concerned to monitor flood zones, especially those are classified potentially high or very high, in order to make aids get targets accurately. BPBD has already maked software for mapping flood zones, but is not flexible for updating with newest district (kecamatan) data. This research is to modify that software as such as it can be updated with newest data, until village (desa) level. Weighted product method is chosen to classify flood zones, because its simplicity. Classification criterias are rainfall, altitude, slope, river runoff, and land cover. Newest data are gotten from BPS, Bappeda and BPBD for 276 village, and need to be preprocessed. Weight of criterias in likert scale are gotten from BPBD. The classification result of potentially flood zones then are shown with QGIS. The implementation of this method give $68 \%$ of accuracy in the very high class of potentially flood zones, and $80.4 \%$ of high class.
\end{abstract}

Keywords: potentially flood zones, classification, weighted product, QGIS

\begin{abstract}
Abstrak
Banjir merupakan masalah tahunan di Kabupaten Bandung. Saat banjir berlangsung beberapa hari, biasanya bantuan berdatangan untuk korban banjir. Badan Penanggulangan Bencana Daerah (BPBD) berkepentingan memantau wilayah rawan banjir, terutama yang termasuk kelas rawan banjir yang tinggi dan sangat tinggi, agar bantuan tepat sasaran. BPBD pernah membuat perangkat lunak membuat pemetaan daerah rawan banjir, namun dinilai tidak fleksibel karena tidak dapat diupdate dengan data terbaru di tingkat kecamatan. Penelitian ini ingin memodifikasi perangkat lunak tersebut sedemikian hingga dapat diupdate dengan data terbaru hingga level desa. Metode Weighted Product dipilih untuk mengklasifikasikan daerah rawan banjir, karena kesederhanaannya. Kriteria untuk klasifikasi daerah rawan banjir adalah curah hujan, ketinggian, kemiringan, limpasan sungai, dan tutupan lahan. Data-data terbaru diperoleh dari BPS, Bappeda dan BPBD untuk 276 desa, dan perlu dilakukan pengolahan data awal. Bobot kriteria dalam skala Likert diperoleh dari BPBD. Hasil klasifikasi daerah rawan banjir dengan Weighted Product ditampilkan dengan QGIS. Implementasi metode ini memberikan hasil akurasi sebesar $68 \%$ pada kelas kerawanan sangat tinggi, dan $80,4 \%$ pada kelas kerawanan tinggi.
\end{abstract}

Kata Kunci: daerah rawan banjir, klasifikasi, weighted product, QGIS. 


\section{PENDAHULUAN}

$\mathrm{K}$ abupaten Bandung merupakan salah satu wilayah rawan banjir. Banyak desa mengalami banjir ketika musim hujan tiba. Banyak kerugian yang dialami masyarakat ketika banjir melanda, kerugian fisik materi berupa barang - barang yang rusak akibat banjir tersebut, atau penyakit akibat air tanah yang kotor. Beberapa daerah rawan banjir di kabupaten Bandung memiliki kepadatan penduduk yang tinggi, misalnya Kecamatan Dayeuhkolot dengan kepadatan penduduk yaitu 10.600 jiwa per kilometer persegi, kecamatan Majalaya dengan 6278 jiwa per kilometer persegi, dan kecamatan Baleendah dengan 6026 jiwa per kilometer persegi. Padatnya penduduk di wilayah ini, karena dulu pusat pemerintah Kabupaten Bandung memang ada di kecamatan Baleendah. Setelah pusat pemerintahan pindah ke Soreang, penduduk nampaknya lebih memilih bertahan di tempat semula, boleh jadi karena sudah nyaman, atau belum ada tempat lain yang lebih nyaman, atau banyaknya perhatian atau bantuan pihak luar saat terjadi banjir.

BPBD Kabupaten Bandung pernah membuat peta klasifikasi rawan banjir pada tahun 2012 melalui PT Geojaya Teknik dengan menggunakan teknik overlay. Teknik ini tidak fleksibel karena tidak bisa di update oleh petugas. Kriteria - kriteria yang dapat memicu banjir seperti drainase sungai, curah hujan, kemiringan lereng, penggunaan lahan, dan ketinggian daerah yang akan digunakan dalam penelitian ini berupa data angka, bukan data berupa peta, sehingga tidak digunakan metode overlay atau penumpukan peta. Lima data kriteria yang akan digunakan untuk mengklasifikasi tingkat kerawanan banjir itu, dalam teori termasuk masalah Multiple Atributte Decision Making (MADM). Beberapa metode dapat diterapkan untuk masalah MADM ini, misalnya SAW, WP, TOPSIS, AHP, dan sebagainya.

Masalah yang akan diteliti dalam penelitian ini adalah :

1. Bagaimana membuat aplikasi GIS untuk klasifikasi tingkat kerawanan banjir wilayah Kabupaten Bandung menggunakan metode Weighted Product?

2. Seberapa baik aplikasi yang dibuat dalam memenuhi kebutuhan pengguna?

Karena pengamatan topografi dilakukan setiap 5 tahun sekali, data curah hujan, penggunaan lahan kering, ketinggian, kemiringan, dan limpasan sungai yang dipakai adalah data tahun 2011 - 2012. Data sampel yang akan diolah akan diambil sampai tingkat desa, sehingga jumlah data yang akan diolah akan cukup banyak. Dari beberapa metode MADM yang ada, akan dipilih metode sederhana agar pemrosesan lebih cepat. Metode Weighted Product dipilih untuk mengolah kriteria yang tidak saling mempengaruhi, misalnya ketinggian suatu daerah tidak terpengaruhi oleh kriteria curah hujan.

\section{LANDASAN TEORI}

\section{A. Weighted Product}

Metode Weighted Product merupakan metode penyelesaian untuk permasalahan multi kriteria yang dapat memberikan bobot terhadap suatu data. Metode ini tidak memerlukan pembentukan matriks perbandingan berpasangan seperti pada metode AHP sehingga memerlukan waktu yang lebih singkat. Metode Weighted Product mirip dengan metode Weighted Sum Model (WSM). Perbedaannya berada dalam proses perhitungannya, dimana WSM menggunakan penambahan sedangkan WP menggunakan perkalian[2]. Preferensi $\mathrm{A}_{\mathrm{i}}$ diberikan pada rumus [2]:

$$
\prod x
$$

Dimana $X_{i j}$ menunjukkan atribut $j$ dari kandidat alternatif $i, w_{j}$ menunjukkan bobot dari atribut $j$, dan $\sum w_{j}=1$. Dalam rumus di atas, $\mathrm{w}_{\mathrm{j}}$ bernilai positif untuk atribut benefit dan bernilai negatif untuk atribut cost [2]. Preferensi tiap alternatif dibandingkan langsung dengan alternatif terbaik di tiap atribut. Untuk atribut benefit nilai terbaik adalah nilai tertinggi, untuk atribut cost nilai terbaik adalah nilai terendah [2]. Preferensi tiap alternatif diberikan pada rumus: 


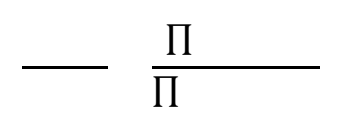

\section{B. Distribusi Frekuensi}

Pada saat mengumpulkan data mentah yang berjumlah besar, seringkali berguna jika kita mendistribusikan data-data tersebut ke dalam kelas atau kategori data serta menentukan banyaknya individu atau anggota dari masing-masing kelas yang disebut sebagai frekuensi kelas. Suatu susunan data dalam bentuk yang disusun berdasarkan kelas atau interval tersebut adalah distribusi frekuensi. Distribusi frekuensi bertujuan untuk menyajikan data dalam bentuk kelas agar perhitungan atau penyajiannya lebih mudah dan teratur. Dalam melakukan distribusi frekuensi terhadap suatu data mentah, terdapat aturan tertentu dalam menentukan jumlah kelasnya, yaitu dengan langkah berikut:

1. Menentukan Range (R), yaitu data terbesar dikurangi data terkecil

2. Menentukan banyaknya kelas $(\mathrm{K})$, dengan rumus $\mathrm{K}=1+3.3 \log \mathrm{n}$

3. Menentukan panjang interval (I), dengan membagi $\mathrm{R}$ dan $\mathrm{K}$, atau $\mathrm{I}=\mathrm{R} / \mathrm{K}$.

\section{Skala Likert}

Pengukuran dengan skala ordinal berasumsi bahwa suatu variabel dapat diurut berdasarkan tingkatan atribut yang dimiliki atau yang dapat diberi ranking. Data yang diperoleh dengan skala ordinal disebut data ordinal, yaitu data berjenjang dimana jarak antara satu data dengan yang lainnya tidak sama. Jadi, skala ordinal adalah skala yang memberikan perbedaan yang membedakan antar data berdasarkan besar kecilnya, tinggi rendahnya, baik buruknya, berpengaruh atau tidak berpengaruhnya, dan sebagainya. Salah satu skala yang umum digunakan dalam menangani data ordinal adalah skala Likert. Skala Likert adalah skala yang dapat digunakan untuk mengukur sikap, pendapat, dan persepsi seseorang tentang suatu gejala atau fenomena. Dalam skala Likert, pertanyaan "Apakah curah hujan menyebabkan suatu desa menjadi rawan banjir?", jawabannya mungkin 1,2,3,4,5 atau 5,4,3,2,1, dengan 5:sangat setuju, 4:setuju, 3:ragu - ragu, 2:tidak setuju, dan 1:sangat tidak setuju.

\section{D. $Q G I S$}

QGIS, sebelumnya dikenal sebagai Quantum GIS, adalah aplikasi Sistem Informasi Geografi desktop opensource dan lintas platform yang menyediakan fasilitas penampilan, pengeditan dan analisis data.[13]. Mirip dengan perangkat lunak GIS yang lain, QGIS mengijinkan pengguna membuat peta dalam banyak layer, menggunakan proyeksi peta yang berbeda. Peta dapat disusun dalam format dan penggunaan yang berbeda. QGIS mengijinkan peta terdiri dari layer raster atau vektor, selain citra gambar geografi.

\section{Metodologi PENELITIAN}

\section{A. Tahapan Penelitian}

Sebelum aplikasi dibuat, dilakukan pengumpulan data terlebih dahulu dengan wawancara dan konsultasi dengan pihak BPBD Kabupaten Bandung untuk mengetahui kriteria apa saja yang paling mempengaruhi kerawanan banjir, kemudian bobot masing - masing kriteria tersebut. Setelah kriteria didapatkan, dilakukan pengumpulan data setiap kriteria tersebut dari 276 desa di Kabupaten Bandung.

Setelah data dikumpulkan dan bobot ditentukan, selanjutnya data diolah, kemudian dihitung dengan metode Weighted Product. Output akhir dari aplikasi akan memberikan kelas kerawanan bagi setiap desa. Setelah didapat nilai kelas kerawanan dari setiap desa, selanjutnya nilai kelas tersebut digunakkan untuk menggambarkan peta kerawanan banjir menggunakan QGIS. Setelah itu melakukan evaluasi dan analisis 
Eko DaRWIYANTO ET.AL.

terhadap hasil serta melakukan pengujian terhadap fungsionalitas sistem dan juga pengujian kesesuaian antara hasil dari metode yang digunakan dengan data kerawanan yang dimiliki BPBD. Gambar 1 menunjukkan metodologi penelitian sistem.

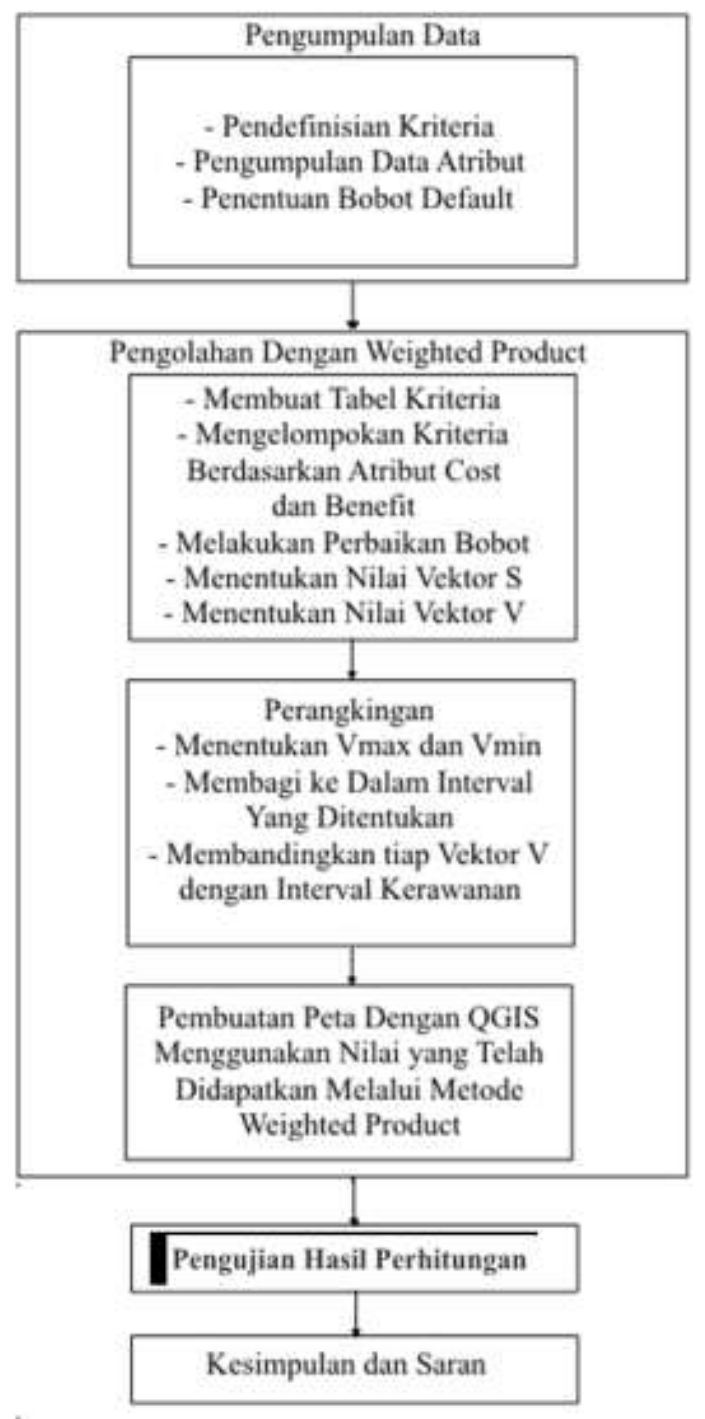

Gambar 1. Tahapan Penelitian

\section{B. Identifikasi dan Pembobotan Kriteria}

Terdapat 5 atribut kriteria yang digunakan dalam penelitian ini, yang akan ditentukan apakah termasuk cost atau benefit. Kriteria tersebut diperoleh dari studi literatur terhadap penelitian sejenis yang pernah dilakukan untuk melihat kriteria yang mempengaruhi banjir, selanjutnya dilakukan wawancara dengan pihak BPBD. Hasilnya diperoleh lima kriteria yang mempengaruhi tingkat kerawanan banjir di Kabupaten Bandung. Kelima kriteria tersebut adalah sebagai berikut: 
1). Curah Hujan (Cost) : semakin tinggi angka curah hujan suatu daerah, maka semakin tinggi kemungkinan air menggenang di daerah tersebut, sehingga semakin tinggi tingkat rawan banjirnya.

2). Ketinggian (Benefit) : semakin tinggi suatu daerah, semakin kecil kemungkinan air meluap.

3). Kemiringan lereng (Benefit) : semakin miring suatu daerah, semakin cepat air mengalir, sehingga semakin kecil kemungkinan air dapat menggenang. Kemiringan lereng ini berkaitan dengan bentuk topografi suatu desa yang terbagi dalam lima tingkat yaitu datar, landai, miring agak curam, curam, dan sangat curam.

4). Tutupan lahan (Cost) : Berkurangnya sawah yang digantikan oleh perumahan berpengaruh terhadap drainase air. Semakin besar penggunaan lahan terbangun di suatu desa maka semakin lambat drainase air.

5). Limpasan Sungai (Benefit) : Kabupaten Bandung dilalui oleh sungai Citarum yang memiliki empat sub DAS yaitu Citarik, Cirasea, Cisangkuy dan Ciwidey. Masing - masing Sub DAS ini melalui masing masing desa, dan memiliki kecepatan limpasan air perdetik yang berbeda. Semakin besar limpasan air perdetik suatu sub DAS yang melalui suatu desa, semakin lancar drainase air melalui sungai di desa tersebut.

Selanjutnya setiap kriteria akan ditentukan bobot pengaruhnya terhadap tingkat kerawaanan banjir, menggunakan skala Likert. Semakin tinggi nilai bobot semakin penting pengaruhnya dalam menyebabkan rawan banjir. Misalkan kriteria curah hujan, maka pertanyaannya adalah "Apakah anda setuju bahwa curah hujan menyebabkan suatu daerah rawan banjir?". Angka 1 menunjukan sangat tidak setuju, angka 5 menunjukan angka setuju.

\section{Sumber-sumber Data}

Data yang diperoleh berupa data atribut 276 desa di Kabupaten Bandung yang berpengaruh terhadap kerawanan banjir seperti curah hujan, ketinggian, kemiringan lereng, limpasan sungai, dan penggunaan lahan. Data beragam atribut tersebut diperoleh dari tiga sumber : BPS, BAPPEDA, dan BPBD Kabupaten Bandung dengan rincian sebagai berikut.

1. Data Primer

Data Primer merupakan data utama aplikasi, data ini meliputi:

a. Tutupan/Lahan Kering : didapatkan dari Badan Pusat Statistik (BPS) Kabupaten Bandung, dengan sumber dari buku Kecamatan Dalam Angka 2012 yang berupa data luas desa dan data luas lahan kering/bangunan.

b. Curah Hujan : didapatkan berupa peta dari BAPPEDA.

c. Limpasan Sungai : Data limpasan sungai dipengaruhi oleh Sub Daerah Aliran Sungai (Sub DAS) yang melalui setiap kecamatan di Kabupaten Bandung. Peta DAS didapat dari BAPPEDA.

d. Ketinggian : Data ketinggian daerah didapatkan dari BPS yang didapatkan dari Buku Kabupaten Bandung Dalam Angka 2012.

e. Kemiringan lereng : Didapatkan dari peta dari BAPPEDA.

2. Data Sekunder

Data sekunder merupakan data pendukung aplikasi, yang meliputi:

a. Peta Batas Administrasi Kabupaten Bandung

Didapatkan dari BAPPEDA yang digunakan sebagai acuan dalam pembuatan peta pada QGIS.

b. Peta Bahaya Bencana Banjir 2012

Didapatkan dari BPBD yang digunakkan sebagai data pembanding pada pengujian kecocokan akurasi aplikasi, nantinya hasil perhitungan aplikasi akan dibandingkan kelas kerawanannya dengan kelas kerawanan yang didapat dari peta ini. 
Eko DarWiyanto Et.al.

\section{Penyiapan Data}

Sebelum data dimasukkan ke dalam database aplikasi, dilakukan penyiapan data, karena input yang diinginkan dalam aplikasi telah tersaji dalam kelas agar perhitungan lebih ringkas dan cepat. Pembagian kelas berdasarkan kepada teori distribusi frekuensi, yang merupakan salah satu teori statistika untuk menyajikan data dalam bentuk kelas. Berikut langkah dalam distribusi frekuensi:

1. Menentukan Range (R), yaitu data terbesar dikurangi data terkecil

2. Menentukan banyaknya kelas $(\mathrm{K})$, dengan rumus $\mathrm{K}=1+3.3 \log \mathrm{n}$

3. Menentukan panjang interval (I), dengan membagi $\mathrm{R}$ dan $\mathrm{K}$, atau $\mathrm{I}=\mathrm{R} / \mathrm{K}$

Untuk masing-masing kriteria, hasilnya adalah sebagai berikut:

\section{1). Kemiringan}

Karena data yang didapatkan sudah berbentuk dalam interval, maka tidak perlu diubah dengan distribusi frekuensi. Tabel 1 menampilkan kelas kemiringan tanah.

TABEL 1

KELAS KEMIRINGAN TANAH

\begin{tabular}{|c|c|}
\hline Tingkat Kemiringan & Kelas Data \\
\hline Datar & 1 \\
\hline Landai & 2 \\
\hline Agak Curam & 3 \\
\hline Curam & 4 \\
\hline Sangat Curam & 5 \\
\hline
\end{tabular}

\section{2). Limpasan Sungai}

Dibagi menjadi 6 kelas, berdasarkan DAS yang melalui setiap desa yang mana angka 1 merupakan DAS dengan limpasan terkecil dan 6 adalah DAS dengan limpasan paling deras. Tabel 2 menampilkan kelas limpasan DAS sesuai urutannya.

TABEL 2

KELAS LIMPASAN SUNGAI

\begin{tabular}{|c|c|}
\hline Nama DAS & Kelas Data \\
\hline Citarik & 1 \\
\hline Ciwidey & 2 \\
\hline Cikapundung & 3 \\
\hline Cisangkuy & 4 \\
\hline Ciminyak & 5 \\
\hline Cisarea & 6 \\
\hline
\end{tabular}

\section{3). Curah Hujan}

Terbagi menjadi 6 kelas interval yang sudah ditentukan dari peta yang didapat dari BAPPEDA, ditunjukkan di Tabel 3. 
TABEL 3

KeLAS CURAH HuJAN

\begin{tabular}{|c|c|}
\hline Intensitas Curah Hujan & Kelas Data \\
\hline $2000 \mathrm{~mm}$ & 1 \\
\hline $2003-2500 \mathrm{~mm}$ & 2 \\
\hline $2503-3000 \mathrm{~mm}$ & 3 \\
\hline $3003-3500 \mathrm{~mm}$ & 4 \\
\hline $3503-4000 \mathrm{~mm}$ & 5 \\
\hline $4003-4500$ & 6 \\
\hline
\end{tabular}

\section{4). Ketinggian}

Untuk data kriteria ketinggian dan tutupan lahan, dilakukan distribusi frekuensi yang telah dipaparkan sebelumnya. Berikut langkah yang dilakukan:

a. Menentukan Range (data terbesar dikurangi data terkecil).

Data terkecil dimiliki desa Pameuntasan dengan ketinggian $500 \mathrm{mdpl}$, data tertinggi adalah desa Neglawangi dengan ketinggian 1812 mdpl, maka Range $=1812-500=1312$

b. Menentukan kelas dengan rumus $\mathrm{K}=1+3.3 \log \mathrm{n}$, dimana $\mathrm{n}$ merupakan total desa yang dijadikan sampel yaitu 276 desa, maka Kelas $=1+3.3 \log 276=9$ kelas

c. $\quad$ Panjang Interval, $\mathrm{I}=\mathrm{R} / \mathrm{K}$, maka pembulatan Interval $=1312 / 9=146$.

Dengan menggunakan perhitungan diatas maka pada kriteria ketinggian dan tutupan kelas dibagi menjadi 9 kelas.

\section{5). Tutupan Lahan}

Preprocessing dilakukan dengan membagi luas lahan kering (bangunan/non sawah) pada setiap desa dengan luas desa lalu dikali 100\%. Tabel 4 menampilkan contoh dari perhitungan yang dilakukan.

TABEL 4

KELAS TUTUPAN LAHAN

\begin{tabular}{|c|c|c|c|}
\hline Nama Desa & $\begin{array}{c}\text { Luas Lahan } \\
\text { Kering (Ha) }\end{array}$ & Luas Desa (Ha) & $\begin{array}{c}\text { Hasil Perhitungan } \\
\text { (\%) }\end{array}$ \\
\hline Panundaan & 76.07 & 321.30 & $23.67 \%$ \\
\hline Ciwidey & 75.10 & 218.30 & $34.4 \%$ \\
\hline Panyocokan & 60.03 & 389.20 & $15.42 \%$ \\
\hline
\end{tabular}

Persentase hasil perhitungan tersebut selanjutnya otomatis terbagi ke dalam kelas oleh aplikasi. Kelas yang digunakan masih sama yaitu terbagi menjadi 9 kelas seperti perhitungan yang telah dipaparkan pada poin 4 . Setelah data dikelaskan dalam interval, kemudian data dimasukkan ke dalam database.

\section{E. Pengolahan Data dengan Weighted Product}

Tahap-tahap utama dalam pemodelan Weighted Product adalah sebagai berikut:

a. Memasukkan nilai dari tiap kriteria

Data yang telah didapatkan pada tahap pengumpulan data dimasukkan kepada database desa.

b. Menentukan bobot dari tiap kriteria (didapat dari pengambil keputusan), dan melakukan normalisasi bobot yang dimasukkan agar total bobot menjadi 1 .

c. Mengalikan seluruh atribut dari tiap alternatif dengan bobotnya, dimana bobot sebagai pangkat positif untuk atribut benefit dan bobot sebagai pangkat negatif pada atribut cost (Vektor S). 
Eko DarWiyanto ET.AL.

Aplikasi GIS Klasifikasi Tingkat...

d. Menjumlahkan seluruh hasil perkalian pada tiap alternatif, untuk mendapatkan nilai preferensi $A_{i}$ (Vektor V).

e. Membuat interval kerawanan yang diperoleh dengan cara menghitung selisih dari nilai maksimum vektor $\mathrm{v}$ dan nilai minimumnya, kemudian membagi selisih tersebut menjadi beberapa kelas interval, yang mana menurut wawancara dengan BPBD Kabupaten Bandung dibagi menjadi 5 kelas yaitu sangat rendah, rendah, menengah, tinggi, dan sangat tinggi.

\section{E. Fungsionalitas Sistem}

Fungsionalitas perangkat lunak yang dibangun meliputi:

1. Masyarakat dapat melihat dan mendapatkan informasi mengenai atribut desa seperti curah hujan, ketinggian, kemiringan, presentase pembangunan lahan, dan limpasan sungai. dan juga kelas kerawanan dari desa yang berada di Kabupaten Bandung

2. Output sistem akan memberikan peta yang telah dikelola dengan menggunakan QGIS sesuai data yang didapatkan dari penghitungan metode Weighted Product pada aplikasi

3. Petugas dapat melakukan aksi kelola data berupa insert, update, dan delete data atribut desa, juga dapat mengubah bobot tiap kriteria.

\section{PENGUJIAN DAN ANALISIS}

\section{A. Uji Fungsionalitas Sistem}

Tampilan aplikasi untuk pengolahan data menggunakan Weighted Product ditunjukkan dalam Gambar 2.

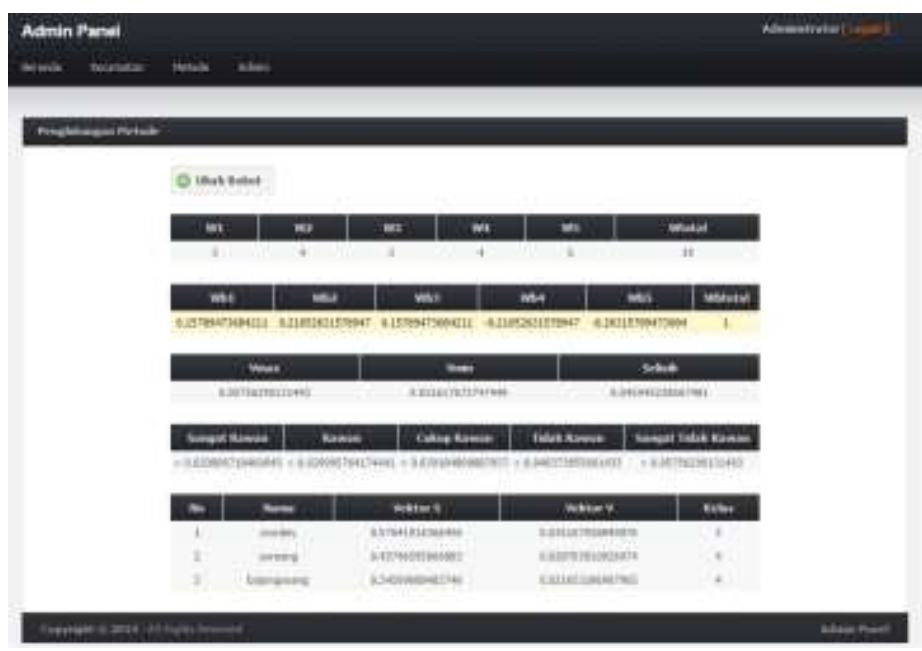

Gambar 2. Tampilan Pengolahan Data Weighted Product

Fungsionalitas aplikasi diuji dengan pendekatan blackbox untuk menemukan fungsi yang tidak benar, kesalahan antar muka, kesalahan kinerja, kesalahan dalam struktur data. Hasil ditunjukkan di Tabel 5, semua fungsionalitas sistem sudah berjalan baik. 
TABEL 5

UII FUNGSIONALITAS SISTEM

\begin{tabular}{|c|c|c|c|c|c|}
\hline Fungsionalitas & Keterangan & Jenis Uji & Data Uji & $\begin{array}{c}\text { Hasil } \\
\text { Pengamatan }\end{array}$ & $\begin{array}{c}\text { Hasil } \\
\text { Uji }\end{array}$ \\
\hline Login & - Login sebagai admin & Blackbox & $\begin{array}{l}\text { Username : admin } \\
\text { Password : admin }\end{array}$ & $\begin{array}{l}\text { Masuk ke } \\
\text { halaman admin }\end{array}$ & Diterima \\
\hline \multirow[t]{3}{*}{ Kelola data desa } & - Insert data desa & Blackbox & $\begin{array}{l}\text { Nama desa: test } \\
\text { Ketinggian: } 100 \\
\text { Kemiringan: } 3 \\
\text { Drainase Sungai: } 10 \\
\text { Curah Hujan: } 3000 \\
\text { Penggunaan: } 40\end{array}$ & $\begin{array}{l}\text { Data masuk ke } \\
\text { tabel desa }\end{array}$ & Diterima \\
\hline & - Update data desa & Blackbox & $\begin{array}{l}\text { Data yang akan diubah: } \\
\text { Nama desa: test }\end{array}$ & $\begin{array}{l}\text { Nama desa } \\
\text { pada tabel desa } \\
\text { berubah }\end{array}$ & Diterima \\
\hline & - Delete data desa & Blackbox & $\begin{array}{l}\text { Data yang akan } \\
\text { dihapus: } \\
\text { Nama desa: test }\end{array}$ & $\begin{array}{l}\text { Nama desa } \\
\text { pada tabel desa } \\
\text { terhapus }\end{array}$ & Diterima \\
\hline Update nilai Vektor $\mathrm{S}$ & $\begin{array}{l}\text { - Update nilai vektor s } \\
\text { berdasarkan hasil } \\
\text { hitung }\end{array}$ & Blackbox & $\begin{array}{l}\text { Data desa dan data } \\
\text { bobot }\end{array}$ & $\begin{array}{l}\text { Nilai vektor S } \\
\text { berubah }\end{array}$ & Diterima \\
\hline Update nilai Vektor $\mathrm{V}$ & $\begin{array}{l}\text { - Update nilai vektor } \\
\text { v berdasarkan hasil } \\
\text { hitung }\end{array}$ & Blackbox & $\begin{array}{l}\text { Data desa dan data } \\
\text { bobot }\end{array}$ & $\begin{array}{l}\text { Nilai vektor V } \\
\text { berubah }\end{array}$ & Diterima \\
\hline Kelola data bobot & - Update data bobot & Blackbox & $\begin{array}{l}\text { Data yang akan diubah: } \\
\text { W1: } 4\end{array}$ & $\begin{array}{l}\text { Nilai berhasil } \\
\text { diubah }\end{array}$ & Diterima \\
\hline Registrasi admin & - Tambah data admin & Blackbox & $\begin{array}{l}\text { Semua field diisi } \\
\text { dengan data yang } \\
\text { diminta }\end{array}$ & $\begin{array}{l}\text { Data admin } \\
\text { sistem diterima }\end{array}$ & Diterima \\
\hline
\end{tabular}

\section{B. Uji Akurasi Sistem}

Data curah hujan, tutupan lahan, ketinggian, kemiringan, dan limpasan sungai dari 276 desa di Kabupaten Bandung dimasukkan ke dalam sistem. BPBD Kabupaten Bandung, sebelumnya telah memiliki data klasifikasi tingkat kerawanan banjir dari expert judgment perwakilan desa. Hasil klasifikasi aplikasi selanjutnya dicocokkan dengan hasil expert judgment tersebut. Hasilnya ditunjukkan di Tabel 6.

TABEL 6

UII AKURASI SISTEM

\begin{tabular}{|c|c|c|c|c|}
\hline No. & Kelas Kerawanan & Desa Yang Sesuai & Total Desa & Persentase Kecocokan \\
\hline 1 & Sangat Tinggi (5) & 40 & 65 & $61.5 \%$ \\
\hline 2 & Tinggi (4) & 86 & 107 & $80.4 \%$ \\
\hline 3 & Menengah (3) & 22 & 51 & $43.1 \%$ \\
\hline 4 & Rendah (2) & 19 & 34 & $56 \%$ \\
\hline 5 & Sangat Rendah (1) & 8 & 19 & $42 \%$ \\
\hline & TOTAL & $\mathbf{1 7 5}$ & $\mathbf{2 7 6}$ & $\mathbf{6 3 . 4 \%}$ \\
\hline
\end{tabular}


Eko DaRWiYANTO ET.AL.

Aplikasi GIS KLASifikasi Tingkat...

Pada kelas kerawanan sangat tinggi yang memiliki akurasi 61.5\%, klasifikasi tidak cocok sebanyak 25 desa, 25 desa menurut aplikasi memiliki kelas kerawanan sangat tinggi (5) namun tidak begitu menurut BPBD. Namun ternyata 25 desa yang tidak cocok tersebut, menurut BPBD memiliki kelas kerawanan tinggi (4), artinya meskipun ada ketidak cocokan sebanyak 25 desa, pergeseran yang terjadi hanya selisih 1 kelas dan masih dalam kelas yang menjadi daerah rawan banjir, karena yang menjadi kawasan rawan banjir dan menjadi prioritas bantuan adalah desa dengan kelas 4 (tinggi) dan 5 (sangat tinggi).

Dalam memetakan kawasan yang memiliki kelas kerawanan rendah, akurasi dari sistem kurang baik, terlihat pada tabel bahwa dalam memetakan kawasan dengan kelas sangat rendah (1), sistem hanya memberikan hasil 42\%. Namun, dengan data yang ada, aplikasi sudah cukup dapat memberikan hasil yang diinginkan. Terutama dalam mengklasifikasikan desa yang memiliki kerawanan tinggi dan sangat tinggi yang memang lebih diperlukan dalam pengklasifikasian daerah rawan banjir di Kabupaten Bandung.

Berikut disampiakan hasil peta dari data keseluruhan dan data setiap kelas.

1) Hasil Peta : Menggunakan bobot awal untuk menguji kecocokan antara hasil klasifikasi dari aplikasi dengan data nyata yang ada di BPBD. Gambar 2 merupakan peta hasil perhitungan dengan bobot dari BPBD.

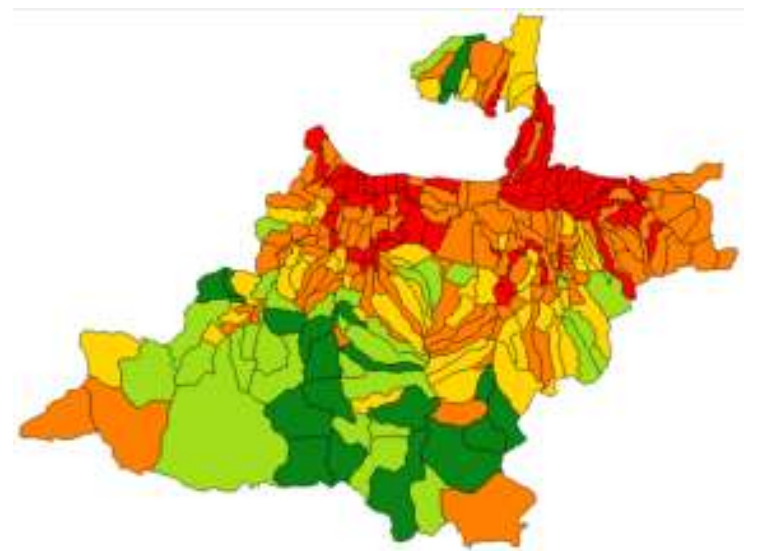

Gambar 3. Peta Hasil Aplikasi

2) Hasil Peta Kelas Sangat Tinggi: Membandingkan peta hasil aplikasi dan data BPBD, dilakukan metode overlay yaitu menumpuk dua peta tersebut untuk melihat berapa jumlah desa yang cocok klasifikasinya. Berdasarkan perhitungan aplikasi terdapat 65 desa yang memiliki kelas kerawanan sangat tinggi. Figure 3 menampilkan peta dengan tingkat kerawanan sangat tinggi (warna ungu). 


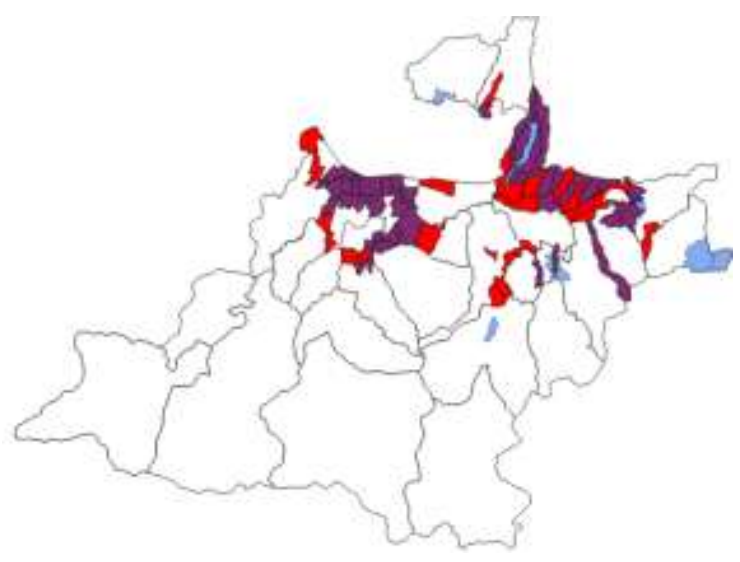

Gambar 4. Peta Pengujian Kelas Sangat Tinggi

Warna ungu pada peta menunjukan desa yang sesuai antara aplikasi dan data BPBD, dari 65 desa yang dihasilkan aplikasi terdapat 44 desa yang sesuai, sehingga dapat diperoleh presentase kecocokan adalah 44/65 x $100 \%$ yaitu sebesar $68 \%$.

3) Hasil Peta Kelas Tinggi: dengan cara yang sama, terdapat 107 desa yang memiliki kelas kerawanan tinggi. Gambar 4 menampilkan peta dengan tingkat kerawanan tinggi.

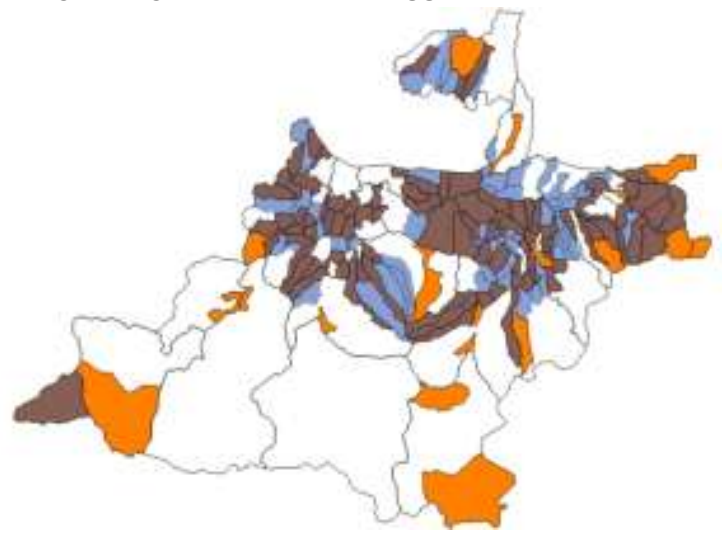

Gambar 5. Peta Pengujian Kelas Tinggi

Warna abu pada peta menunjukan desa yang sesuai antara aplikasi dan data BPBD, dari 107 desa yang dihasilkan aplikasi terdapat 86 desa yang sesuai, sehingga dapat diperoleh presentase kecocokan adalah $86 / 107$ x $100 \%$ yaitu sebesar $80.4 \%$.

\section{Analisis Hasil Pengujian Akurasi Aplikasi}

Data topografi yang dipakai adalah data tahun 2011-2012. Data terbaru belum diperoleh. Semua data kemiringan, ketinggian, curah hujan, dan limpasan sungai tidak jauh berbeda. Yang berubah adalah penggunaan lahan kering seiring dengan pembangunan perumahan dan bangunan lain yang terus tumbuh di 
Eko Darwiyanto et.al.

Aplikasi GiS Klasifikasi Tingkat...

wilayah Kabupaten Bandung. Namun, dengan data yang ada, aplikasi sudah cukup dapat memberikan hasil yang diinginkan. Terutama dalam mengklasifikasi desa yang memiliki kerawanan tinggi dan sangat tinggi.

\section{KESIMPULAN}

Kesimpulan yang diperoleh dari penelitian ini adalah sebagai berikut:

1. Aplikasi dapat dibangun dengan memanfaatkan data curah hujan, ketinggian, kemiringan lereng, volume limpasan sungai, dan tutupan lahan dari 276 desa yang perlu dilakukan pengolahan awal dulu.

2. Tingkat akurasi kecocokan klasifikasi untuk kelas kerawanan tinggi sebesar $67 \%$, untuk kelas kerawanan tinggi yang mencapai $80.4 \%$.

Saran untuk penelitian lanjutan adalah digunakannya data curah hujan, ketinggian, kemiringan lereng, volume limpasan sungai, dan tutupan lahan terbaru dari setiap desa untuk mendapatkan tingkat keakuratan klasifikasi yang lebih tinggi.

\section{REFERENCES}

[1] Turban, Efraim., \& Jay E. Aronson, Decision Support Systems And Intelligent Systems Sixth Edition, USA: Prentice Hall, 2001.

[2] Limbong,T, Sistem Pendukung Keputusan - Weighted Product (WP), 2014, tersedia di http://www.academia.edu/3666587/ Sistem_Pendukung_Keputusan__-_Weighted_Product_WP

[3] Evangelos Triantaphyllow and Chi-Tun Lin, Development and Evaluation of Five Fuzzy Multiattribute Decision-Making Methods, International Journal of Approximate Reasoning 1996; 14:281-310

[4] Kusumadewi, Sri, Fuzzy Multi-AttributeDecision Making (Fuzzy MADM), Graha Ilmu, Yogyakarta, 2006

[5] Erlangga, Prayogi, Optimalisasi Penentuan Lokasi Pembangunan SPBU MenggunakanMetode Fuzzy MADM dengan Weighted Product dan Dempster-ShaferAnalytical Hierarchy Process (DS/AHP)(Studi Kasus: PT. Pertamina (Persero) Marketing Operation Regional VI KalimantanCabang Pontianak), Skripsi, Universitas Telkom, Bandung, 2014.

[6] Ningrum,W.A, Sistem Pendukung Keputusan untuk Merekomendasikan TV Layar Datar Menggunakan Metode Weighted Product (WP), Artikel Ilmiah, Universitas Kristen Satya Wacana, Salatiga, 2012

[7] Syaukani, M, Pemodelan Sistem Pendukung Keputusan Kelompok dengan Metode Fuzzy Weighted Product untuk Diagnosis Penyakit Pneumonia, Jurnal Teknologi Vol 5 No 1, Institut Sains \& Teknologi Akprind, Yogayakarta, 2012

[8] Heryani, R, Analisis Kerawanan Banjir Berbasis Spasial Menggunakan Analytic Hierarcial Proccess (AHP) Kabupaten Maros, 2013, tersedia di : http://repository.unhas.ac.id/bitstream/handle/123456789/10071/jurnal\%20Rosma\%20Heryani\%20(h22109259).pdf;sequence=1

[9] Hidayanti, Yeni dkk, Analysis and Implementation Fuzzy Multi-Attribute Decision Making SAW Method for Selection of HighAchieving Students in Faculty Level, IJCSI International Journal of Computer Science Issues, Vol. 10, Issue 1, No 2, January 2013

[10] Kusumadewi, Sri dan Purnomo, Hari, Aplikasi Logika Fuzzy Untuk Pendukung Keputusan Edisi 2, Graha Ilmu, Yogyakarta, 2010

[11] Prof DR.H. Djaali, DR. Pudji Muljono, Pengukuran dalam Bidang Pendidikan, 2007, tersedia di: https://books.google.co.id/books?isbn=9790250584

[12] Supranto, J, Statistik Teori dan Aplikasi Edisi 6, Penerbit Erlangga, Jakarta, 2000

[13] QGIS Official Website, http://www.qgis.org 